\title{
Adverse Impact of Corticosteroids on Rotator Cuff Tendon Health and Repair: A Systematic Review of Basic Science Studies
}

\author{
Richard N. Puzzitiello, M.D., Bhavik H. Patel, B.S., Enrico M. Forlenza, B.S., \\ Benedict U. Nwachukwu, M.D., M.B.A., Answorth A. Allen, M.D., Brian Forsythe, M.D., \\ and Matthew J. Salzler, M.D.
}

\begin{abstract}
Purpose: To evaluate the in vitro effects of corticosteroid injections (CSIs) on rotator cuff tendon (RCT). Methods: A systematic review of the MEDLINE database was performed according to Preferred Reporting Items for Systematic Reviews and Meta-Analyses guidelines for all studies reporting on adverse biochemical and biomechanical effects of CSIs on RCT. Results: Sixteen studies were identified that had been published in the last 15 years on the effects of corticosteroids on RCTs. Eight of these studies were on human RCTs, 6 were on rat tendons, 1 considered both human and rat tendons, and 1 was on dog tendon. Five studies analyzed the effects of corticosteroids on the biomechanical properties of RCT or rotator cuff repair, whereas the remaining observed the cellular and molecular effects of CSIs on RCT. Corticosteroids suppress an inflammatory response, induce apoptosis, and have negative effects on collagen and tendon cell viability in RCTs. The mechanical properties, including load to failure of RCTs and rotator cuff repair anchor pull-out strength, also are decreased by CSIs. These in vitro effects appear to be transient as well as frequency and dose dependent. Conclusions: On a molecular level, CSIs decrease cellular proliferation, alter collagen and extracellular matrix composition, impede inflammatory pathways, decrease cellular viability, increase adipocyte differentiation, and increase apoptosis. These changes can be seen as early as 24 hours after corticosteroid exposure, last as long as 2 to 3 weeks, and are exacerbated by increased doses and decreased latency between doses. Biomechanical studies demonstrate that these changes result in decreased maximal load to failure, tendon stiffness, and suture anchor pull-out strength in rat shoulders up to 2 weeks but not at 3 and 4 weeks, post-CSI. Clinical Relevance: Shoulder subacromial steroid injection is common, and practitioners should be aware of results both positive and deleterious.
\end{abstract}

From Tufts Medical Center, Boston, Massachusetts (R.N.P., M.J.S.); Rush University Medical Center, Chicago, Illinois (B.H.P., E.M.F., B.F.); and Hospital for Special Surgery, New York, New York (B.U.N., A.A.A.), U.S.A.

The authors report the following potential conflicts of interest or sources of funding: B.F. reports personal fees from Elsevier, personal fees from Arthrex, personal fees from Jace Medical, grants from Smith $\theta$ Nephew, personal fees from Stryker, grants from Ossur, from null, outside the submitted work. M.J.S. reports medical/orthopaedic publications editorial/governing board: Arthroscopy, Journal of Bone and Joint Surgery-American; and board member/committee appointments for a society: American Orthopaedic Society for Sports Medicine. Full ICMJE author disclosure forms are available for this article online, as supplementary material.

Received November 11, 2019; accepted January 13, 2020.

Address correspondence to Richard N. Puzzitiello, M.D., 110 Beverly St. Apt 805, Boston MA 02114.E-mail: Richard.n.puzzitiello@gmail.com

(C) 2020 Published by Elsevier on behalf of the Arthroscopy Association of North America. This is an open access article under the CC BY-NC-ND license

(http://creativecommons.org/licenses/by-nc-nd/4.0/).

2666-061X/191358

https://doi.org/10.1016/j.asmr.2020.01.002
$\mathbf{R}$ otator cuff tendon (RCT) pathology is the most common cause of shoulder pain. ${ }^{1}$ Rotator cuff tendinosis, which refers to processes such as impingement, rotator cuff fraying, partial-thickness tears, and tendinitis, is a normal element of human aging. ${ }^{1,2}$ While often asymptomatic, RCT pathology can be a source of pain and significantly impact patients' quality of life. ${ }^{3}$ Corticosteroid injections (CSIs) into the subacromial space have served as a valuable treatment modality to the physician treating patients with RCT pathology refractory to conservative management, as they have demonstrated to improve symptoms in the short term. ${ }^{3-6}$ However, CSIs have failed to consistently provide long-term pain relief, and recent studies suggest that CSIs may even predispose to worse longterm outcomes, such as pathologic progression or surgical failure..$^{4,5,7-9}$ 


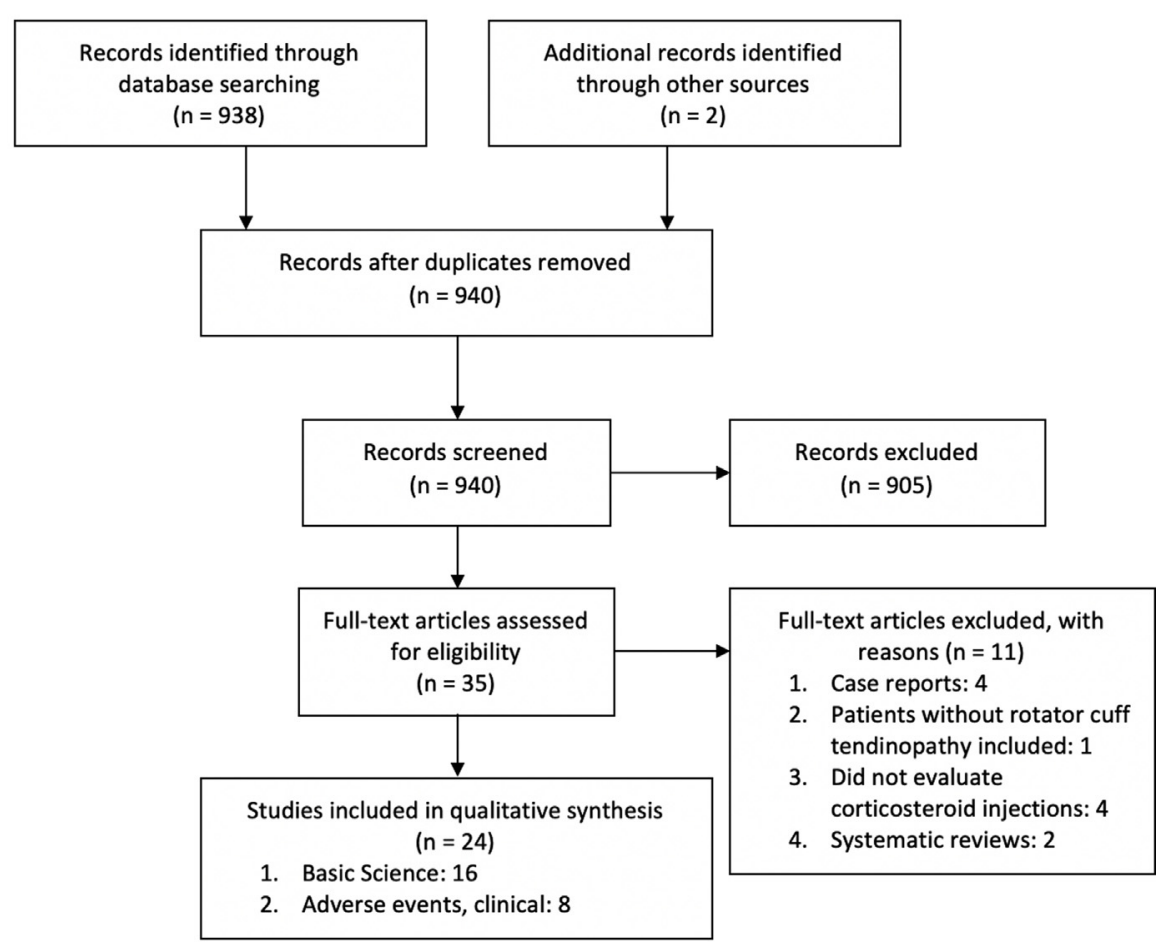

Fig 1. Preferred Reporting Items for Systematic Reviews and Meta-Analyses (PRISMA) flow diagram for study inclusion.
Traditionally, inflammation was believed to be the main driver of pain related to RCT pathology. ${ }^{10}$ Corticosteroids, which have potent anti-inflammatory properties, were thought to directly counteract this process and have since become a popular treatment modality for RCT pathology. ${ }^{11}$ However, recent studies have shown that RCT pathology is more consistent with a failed healing response rather than a traditional inflammatory reaction. ${ }^{9,12}$ Normal tendon healing is characterized by sequential inflammatory, proliferative, and remodeling phases, which require fibroblast proliferation, angiogenesis, and nerve ingrowth. ${ }^{8,13-15}$ It has been hypothesized that the long-term negative effects of CSIs for RCT pathology may be due to altered release of toxins and the inhibition of collagen formation, extracellular matrix molecules, and granulation tissue, all of which are central to the healing process. ${ }^{4,11}$

The basic science that underpins the relationship between CSIs and RCT biology and healing remains poorly understood. Given the recent increased interest in the use of CSIs to treat RCT pathology, there is a need for a comprehensive review to better characterize this relationship. A more complete understanding of the impact of CSIs have on the rotator cuff is necessary to determine what their application should be in the clinical setting. Therefore, the purpose of this systematic review is to evaluate the in vitro effects of CSIs on the RCT. We hypothesized that CSIs would have deleterious effects on RCTs in vitro.

\section{Methods}

\section{Systematic Review and Study Inclusion}

In May 2019, a systematic review of the MEDLINE database was performed according to the Preferred Reporting Items for Systematic Reviews and MetaAnalyses guidelines ${ }^{16}$ (Fig 1). The PubMed interface was used to identify all studies published in the last 15 years, reporting on biochemical, histologic, or biomechanical effects of CSIs for rotator cuff tears. Specifically, the following search terms were used, with no date restriction applied: "rotator cuff OR supraspinatus OR infraspinatus OR subscapularis AND (injection OR steroid OR corticosteroid OR cortisone OR glucocorticoid OR methylprednisolone OR triamcinolone OR dexamethasone OR betamethasone)." The titles and abstracts of articles identified by this query were then screened separately by 2 independent reviewers (R.N.P., B.H.P.) to include studies that were published in the English language and reported on laboratory findings of the effects corticosteroids have on human or animal RCT. Following screening, full-text assessments of all identified publications were performed to confirm inclusion. If there was any ambiguity regarding the potential inclusion of a study based on the title or abstract, a full-text review of that paper was performed. Any study not published within the past 15 years was excluded. Studies were excluded if they did not have a control group, did not sample RCT or greater tuberosity, 
Table 1. Methodologic Characteristics of Included Laboratory Studies

\begin{tabular}{|c|c|c|c|c|c|c|c|}
\hline Authors & Journal & Year & $\begin{array}{l}\text { Rotator Cuff } \\
\text { Tendon Source }\end{array}$ & $\begin{array}{l}\text { Corticosteroid } \\
\text { Exposure }\end{array}$ & $\begin{array}{c}\text { Tested } \\
\text { Substrate }\end{array}$ & Dose/Concentration & Timing of Assessment \\
\hline Muto et al. ${ }^{18}$ & JOR & 2013 & Intact human & In vitro & TA, PRP & $0.1 \mathrm{mg} / \mathrm{mL} \mathrm{TA}$ & $1,7,14,21 \mathrm{~d}$ \\
\hline Lee et al. ${ }^{19}$ & KSSTA & 2015 & Injured rat & In vivo & MP & $0.6 \mathrm{mg} / \mathrm{kg}$ & $\begin{array}{c}\text { Gene expression: } 1,3,7, \\
14, \text { and } 42 \mathrm{~d} \\
\text { IHC: } 14 \text { and } 42 \mathrm{~d}\end{array}$ \\
\hline Dean et al. ${ }^{20}$ & BJSM & 2014 & Injured human & In vivo & MP & $40 \mathrm{mg}$ & $\begin{array}{l}\text { Immediately before } \\
\text { treatment, } 7 \mathrm{wk} \text { post }\end{array}$ \\
\hline Tilley et al. ${ }^{21}$ & BJR & 2014 & Injured human & In vivo & Unspecified & Unspecified & $\begin{array}{l}\text { Immediately prior to } \\
\text { treatment, } 7 \text { weeks post }\end{array}$ \\
\hline Harada et al. ${ }^{22}$ & BJR & 2014 & Intact human & In vitro & TA & $\begin{array}{l}1 \text { or } 2 \text { doses of } 0.1 \mathrm{mg} / \mathrm{mL} \\
\text { at } 7-, 14-, \text { or } 21-\mathrm{d} \text { intervals, } \\
\text { or } 1 \text { dose of } 1.0 \mathrm{mg} / \mathrm{mL}\end{array}$ & $1,7,14,21 \mathrm{~d}$ \\
\hline Nakamura et al. ${ }^{23}$ & JOR & 2015 & $\begin{array}{l}\text { Injured human, } \\
\text { and rat }\end{array}$ & In vivo & DEXA, HA & $\begin{array}{c}0.01,0.1,0.5,1.0 \mathrm{mg} / \mathrm{mL} \\
\text { DEXA or HA (human), } 0.1 \\
\mu \mathrm{L} / \mathrm{g} \text { DEXA or HA (Rat) }\end{array}$ & $\begin{array}{l}\text { Humans: After } 24-\mathrm{h} \\
\text { culture } \\
\text { Rats: } 24 \text { h, } 2 \text { wk, } 4 \text { wk }\end{array}$ \\
\hline Jo et al. ${ }^{24}$ & AJSM & 2017 & Injured human & In vitro & DEXA and PRP & $1 \mu \mathrm{M}$ & $5 \mathrm{ds}$ \\
\hline Ramírez et al. ${ }^{25}$ & $\begin{array}{l}\text { Connective Tissue } \\
\text { Research }\end{array}$ & 2018 & Injured human & In vivo & CSI & $\begin{array}{l}\text { 1-4 injections of } \\
\text { unspecified dose }\end{array}$ & NR \\
\hline Ji et al. ${ }^{26}$ & $\begin{array}{l}\text { Journal of Microbiology } \\
\text { and Biotechnology }\end{array}$ & 2019 & Injured human & In vitro & DEXA & $1 \mu \mathrm{M}$ & $10 \mathrm{~min}, 1 \mathrm{~h}, 2 \mathrm{~h}$ \\
\hline Tempfer et al. ${ }^{27}$ & Acta Orthopaedica & 2009 & Healthy human & In vitro & TA & $40 \mathrm{mg} / \mathrm{mL}$ & $\begin{array}{c}0 \mathrm{~h}, 24 \mathrm{~h}, 48 \mathrm{~h}, 96 \mathrm{~h}, 1 \mathrm{wk}, \\
2 \mathrm{wk}\end{array}$ \\
\hline Wei et al. ${ }^{28}$ & JBJS & 2006 & Injured rat & In vivo & MP & $0.6 \mathrm{mg} / \mathrm{kg}$ & $1,3,5 \mathrm{wk}$ \\
\hline Dolkart et al. ${ }^{29}$ & JSES & 2017 & Healthy rat & In vivo & MTA & $\begin{array}{c}1 \text { or } 3 \text { weekly doses of } 0.66 \\
\mathrm{mg} / \mathrm{kg}\end{array}$ & $\mathrm{l}$ and $4 \mathrm{wk}$ postinjection \\
\hline Mikolyzk et al. ${ }^{30}$ & JBJS & 2009 & Injured rat & In vivo & MP & $0.6 \mathrm{mg} / \mathrm{kg}$ & $\begin{array}{l}1,3, \text { and } 5 \text { wk after } \\
\text { injection }\end{array}$ \\
\hline Maman et al. ${ }^{31}$ & AJSM & 2016 & Injured rat & In vivo & MTA & $\begin{array}{c}1 \text { or } 3 \text { once weekly } 0.6 \mathrm{mg} / \\
\mathrm{kg}\end{array}$ & l wk after injection \\
\hline Nuelle et al. ${ }^{32}$ & $\begin{array}{l}\text { Journal of Orthopaedic } \\
\text { Translation }\end{array}$ & 2016 & Healthy dog & In vitro & BM, TA, MTA & $\begin{array}{c}5 \mathrm{mg} / \mathrm{mL}, 40 \mathrm{mg} / \mathrm{mL}, 40 \\
\mathrm{mg} / \mathrm{mL} \text {, respectively }\end{array}$ & $1,7 \mathrm{~d}$ \\
\hline Ghellioni et al. $^{33}$ & $\begin{array}{c}\text { Revista Brasileira de } \\
\text { Ortopedia }\end{array}$ & 2015 & Healthy rat & In Vivo & MP & $\begin{array}{l}\text { Three doses of } 0.6 \mathrm{mg} / \mathrm{kg}, 6 \\
\mathrm{mg} / \mathrm{kg} \text { at } 24 \mathrm{~h} \text { and } 7 \mathrm{~d} \text { after } \\
\text { first dose }\end{array}$ & $1,7,14 \mathrm{~d}$ \\
\hline
\end{tabular}

AJSM, American Journal of Sports Medicine; BJR, Bone $\theta$ Joint Research; BJSM, British Journal of Sports Medicine; BM, betamethasone; DEXA, dexamethasone; HA, hyaluronic acid; IHC, immunohistochemistry; JBJS, Journal of Bone and Joint Surgery; JOR, Journal of Orthopedic Research; JSES, Journal of Shoulder and Elbow Surgery; KSSTA, Knee Surgery, Sports Traumatology, Arthroscopy; MP, methylprednisolone; MTA, methyl prednisolone acetate; NR, not reported; PRP, platelet-rich plasma; TA, triamcinolone acetonide. 


\begin{tabular}{|c|c|c|c|c|c|c|c|c|}
\hline Authors & $\begin{array}{l}\text { Morphologic } \\
\text { Changes }\end{array}$ & $\begin{array}{c}\text { Cellular } \\
\text { Proliferation }\end{array}$ & $\begin{array}{l}\text { Inflammatory } \\
\text { Cytokines }\end{array}$ & $\begin{array}{l}\text { Col I/ } \\
\text { Col III }\end{array}$ & MMP & Apoptosis & $\begin{array}{c}\text { Cell } \\
\text { Viability }\end{array}$ & Conclusion \\
\hline$\overline{\text { Muto et al. }}{ }^{18}$ & + & $\downarrow$ & & & & $\uparrow$ & $\downarrow$ & $\begin{array}{l}\text { The deleterious effect of TA was prevented by PRP, which can be used as a protective } \\
\text { agent for patients receiving local TA injections. }\end{array}$ \\
\hline Lee et al. ${ }^{19}$ & - & & $\downarrow$ & $\downarrow$ & - & - & & $\begin{array}{l}\text { A subacromial steroid injection may alter the collagen composition and extracellular } \\
\text { matrix and interfere with the healing process in an acute tear, but these alterations } \\
\text { seem to become normalized after the early inflammatory healing phase. }\end{array}$ \\
\hline Dean et al. ${ }^{20}$ & & & & & & $\uparrow^{*}$ & & $\begin{array}{l}\text { The increases in cell proliferation, vascularity, and HIF- } 1 \alpha \text { after surgical rotator cuff } \\
\text { repair appear consistent with a proliferative healing response, and these features } \\
\text { are not seen after CSI. The increase in the glutamate receptor NMDAR } 1 \text { after GCI } \\
\text { raises concerns about the potential excitotoxic tendon damage that may result from } \\
\text { CSI. }\end{array}$ \\
\hline Tilley et al. ${ }^{21}$ & - & & & & & & & $\begin{array}{l}\text { Neither CSI or SAD altered tissue structural properties, suggesting functional recovery } \\
\text { does not equate to recovery of tissue properties. }\end{array}$ \\
\hline Harada et al. ${ }^{22}$ & + & & & & & $\uparrow$ & $\downarrow$ & $\begin{array}{l}\text { A } 0.1 \mathrm{mg} / \mathrm{mL} \text { dose of } \mathrm{TA} \text { temporarily decreased cell viability and increased cell } \\
\text { apoptosis, which was recovered at } 21 \text { days; however, } 1 \mathrm{mg} / \mathrm{mL} \text { of TA caused } \\
\text { irreversible damages. An interval }>3 \mathrm{wk} \text { was needed to safely readminister TA. }\end{array}$ \\
\hline Nakamura et al. ${ }^{23}$ & + & $\downarrow$ & & & & $\uparrow$ & & $\begin{array}{l}\text { Although decreased cell proliferation and delayed healing in the CS group were noted } \\
2 \text { weeks after surgery, no significant differences were found among the } 3 \text { groups } 4 \\
\text { weeks after surgery. }\end{array}$ \\
\hline Jo et al. ${ }^{24}$ & & $\downarrow$ & $\downarrow$ & - & $\downarrow$ & $\uparrow$ & $\downarrow$ & $\begin{array}{l}\text { The addition of PRP avoids the deleterious effects of corticosteroids on tenocytes but } \\
\text { does not interfere with the anti-inflammatory effects of them }\end{array}$ \\
\hline Ramírez et al. ${ }^{25}$ & & & & & & $\uparrow$ & & $\begin{array}{l}\text { The administration of corticosteroid is associated with a greater amount of apoptosis at } \\
\text { the insertion site of the rotator cuff (rupture edge) in patients who received CSI + } \\
\text { RCR, compared with RCR alone. }\end{array}$ \\
\hline Ji et al. ${ }^{26}$ & & & $\downarrow \dagger$ & & & & & $\begin{array}{l}\text { DEXA promoted nuclear localization of NF-kB but was not effective in inhibiting the } \\
\text { inflammatory response of TNF- } \alpha \text { stimulated RCT. }\end{array}$ \\
\hline Tempfer et al. ${ }^{27}$ & + & $\downarrow$ & & & $\downarrow$ & & & $\begin{array}{l}\text { TA caused changes correlating with reduction in the cellular capacity for tendon } \\
\text { repair, changes in cellular differentiation (increased chondrocytes and adipocytes), } \\
\text { cellular degradation, and decreased cellular proliferation and collagen synthesis } \\
\text { rate. }\end{array}$ \\
\hline Wei et al. ${ }^{28}$ & & & & $\downarrow$ & & & & $\begin{array}{l}\text { A single dose of corticosteroid does not alter the acute phase response of an injured } \\
\text { rotator cuff tendon in the rat. However, the same steroid dose in uninjured tendons } \\
\text { initiates a short-term response equivalent to that of structural injury. }\end{array}$ \\
\hline Nuelle et al. ${ }^{32}$ & & & & & & & $\downarrow$ & $\begin{array}{l}\text { Peritendinous injection of lidocaine, betamethasone, and methylprednisolone results } \\
\text { in significant supraspinatus tenotoxicity in vitro. }\end{array}$ \\
\hline Ghellioni et al. $^{33}$ & $\downarrow$ & $\downarrow$ & & & & & & $\begin{array}{l}\text { There is a dose-dependent reduction of mechanical resistance and histological } \\
\text { modifications of rotator cuff tendon exposed to corticosteroids. }\end{array}$ \\
\hline
\end{tabular}

Col I, collagen type I; Col III, collagen type III; CS, corticosteroids; CSI, corticosteroid injection; DEXA, dexamethasone; GCI, glucocorticoid injection; HIF-1 $\alpha$, hypoxia-inducible factor $1 \alpha$; MMP, matrix metalloproteinase; NF-kB, nuclear factor-kB; NMDARl, N-methyl-D-aspartate receptor 1; PRP, platelet-rich plasma; RCR, rotator cuff repair; RCT, rotator cuff tendon; SAD, subacromial decompression; TA, triamcinolone acetonide; TNF-alpha, tumor necrosis factor- $\alpha$.

*This study found increased NMDAR1 receptor expression, which was hypothesized to be a risk for increase excitotoxic cell damage.

${ }^{\dagger}$ This investigation observed the downstream proteins, which are the effect of TNF- $\alpha$ activation, had increased nuclear localization steroid exposure. 
or were not specific to RCT/rotator cuff repair (RCR). All systematic reviews and case reports also were excluded. Studies listed in the references section of all studies meeting the aforementioned inclusion and exclusion criteria also were screened and evaluated for potential inclusion in this review.

\section{Data Collection and Presentation}

For all included studies, outcomes were categorized into effects on cellular/structural morphology, cellular proliferation/senescence, cell viability, inflammatory response, collagen composition, metalloproteinase expression, apoptosis, or biomechanical strength. Given the variety of reporting methodology, meta-analyses were not performed. Instead, results were synthesized qualitatively and stratified into sections for biochemical data, cellular changes/histology data, and biomechanical data. All information from included studies was tabulated using Microsoft Excel 365 (Redmond, WA).

\section{Evaluation of Literature Quality}

Two reviewers (R.N.P., B.H.P.) independently appraised the quality of each included study. As none of these were randomized controlled trials, evaluation was performed by use of the Methodological Index for NonRandomized Studies (MINORS) criteria. $^{17}$ MINORS criteria assess 8 critical aspects of study design for noncomparative studies and an additional 4 aspects of study design for comparative studies. Each item is given a score of 0 if information is not reported, 1 if information is reported but inadequate, and 2 if information is reported and adequate. Therefore, the maximum possible score is 16 for comparative studies and 24 for noncomparative studies. If there was any discrepancy between the results of the 2 reviewers, the item in question was discussed with the senior author who made the final determination of MINORS score.

\section{Results}

\section{Laboratory Studies}

Sixteen studies were identified that had been published in the last 15 years on the effects of corticosteroids on RCTs. Eight of these studies were on human RCTs, 6 were on rat tendons, 1 considered both human and rat tendons, and 1 was on dog tendon. Five studies analyzed the effects of corticosteroids on the biomechanical properties of RCT or RCR, whereas the remaining observed the cellular and molecular effects of CSIs on RCT (Table 1). ${ }^{18-33}$

\section{Molecular}

Several studies showed molecular effects of decreased cellular proliferation/senescence and decreased capacity for tendon repair and cellular migration, and thus healing ${ }^{23,24,27}$ (Table 2). ${ }^{18-28,32,33}$ These effects on cellular proliferation were visualized directly at 48 and 96 hours after treatment and demonstrated indirectly by decreased proliferating cell nuclear antigen (a protein essential for DNA replication and repair) expression 2 weeks after corticosteroid exposure. ${ }^{23,27}$ Decreased capacity for physiologic tendon repair and cellular migration was demonstrated by decreased levels of matrix metalloproteinase (MMP) and increased levels of tissue inhibitors of metalloproteinases after exposure to corticosteroids. ${ }^{24,27}$

Studies also showed a decrease in the ratio of type I to type III collagen and other extracellular matrix (ECM) proteins ${ }^{19,24,27}$ (Table 2). Type I to type III collagen ratio was decreased at 7 days ${ }^{19,28}$ but not at 1 day $^{24}$ or $14^{19}$ days on gene expression or secretion analysis. Furthermore, the study by Tempfer et al. $^{27}$ found a differentiation process occurred after corticosteroid exposure that resulted in increased numbers of adipocytes and chondrocytes 2 weeks after exposure.

Several studies also observed alterations in the inflammatory pathway caused by corticosteroid exposure $^{19}$ (Table 2). A decrease in the gene expression of tumor necrosis factor- $\alpha$ was seen at 3 days after steroid exposure, but no significant changes were observed at $1^{24}$ or 7 days. ${ }^{19}$ Furthermore, Kim et al. ${ }^{34}$ discovered decreased levels of SF-1 expression (a potent chemotactic and angiogenic factor) after corticosteroid exposure. Finally, the study by Jo et al. ${ }^{24}$ found that corticosteroids also decreased the expression of proinflammatory cytokines and decreased anti-inflammatory cytokines.

Corticosteroid exposure results in an increase in apoptotic cells and a decrease in cellular viability and cellular metabolism $^{18,22,25,36}$ (Table 2). Cellular viability was shown to be reduced 14 days after exposure but not at 21 days after a single dose. ${ }^{18}$ If a second CSI was administered within 7 or 14 days of the first, cellular viability did not return to normal, but 21 day latency between doses did result in a return of viability. ${ }^{22}$ Greater percentages of apoptotic cells after corticosteroid exposure were directly visualized in 3 studies $^{18,22,25}$ and indirectly in 1 study by showing increased $N$-methyl-D-aspartate receptor 1 glutamate receptor expression (thus greater susceptibility to oxidative stress and apoptosis induction). ${ }^{20}$ Of note, the observational biopsy study by Ramírez et al. ${ }^{25}$ found that patients who received a CSI before RCR had a $200 \%$ increase in the amount of apoptotic cells compared with those who only received an RCR.

\section{Histologic}

Exposure to corticosteroids caused loss of normal tenocyte and collagen morphology. These changes included loss of cellular orientation, increased polygonal and flattened appearance of cells, and decreased vascular proliferation. These changes were observed at 
7 days $^{33}$ but not 21 days after low dose corticosteroid exposure. ${ }^{18,22}$ However, the histologic appearance did not return to normal at 21 days after high-dose corticosteroid exposure. ${ }^{18,22}$ Changes of collagen appearance on micro- and ultra-structural analysis, including irregular collagen arrangement and increased apoptotic cells, were seen 24 hours $^{23}$ after corticosteroid exposure, but not at 2 weeks ${ }^{19,23}$ or 7 weeks post-CSI. ${ }^{21}$

\section{Biomechanical}

All 5 biomechanical studies were performed on a rat model. Four of these reported a significant decrease in load to failure and stiffness in healthy and injured tendons treated with CSIs compared with a control $^{12,30,31,33}$ or with hyaluronic acid. ${ }^{23}$ In addition to showing altered RCT biomechanics, the study by Maman et al. ${ }^{31}$ also demonstrated significantly decreased greater tuberosity bone volume density on micro-computed tomography 1 week after 3 consecutive methylprednisolone acetate injections. The remaining study showed a decrease in suture anchor pull-out strength in rat shoulders receiving CSIs. ${ }^{29}$

Three of these studies explored the temporal relationship between an injection and biomechanical properties: there is a significant decrease in load to failure and stiffness of RCT, as well as suture anchor pullout strength, one $^{29,30}$ and two ${ }^{20}$ weeks following CSI. However, there is no change in any of these biomechanical properties at three $^{30}$ and four ${ }^{23,29}$ weeks after CSI.

Three of these studies elucidated dose-dependent relationships between CSIs and biomechanical properties: there was no difference in load to failure in injured RCTs treated with l CSI compared with those treated with 3 once-weekly CSIs. ${ }^{29,31}$ However, healthy RCTs treated with 3 once-weekly CSIs had significantly decreased load to failure and stiffness compared with the control, whereas a single CSI showed no effect on this group. ${ }^{29}$ Furthermore, greater tuberosity volume density was significantly lower after 3 once-weekly CSIs but not after a single CSI. ${ }^{31}$ The study by Ghellioni et al. ${ }^{33}$ found that increasing concentrations of CSI had greater detrimental effects on RCT mechanical resistance.

\section{Discussion}

The results of this systematic review of suggest that particular timing and dosages of CSIs have deleterious effects on RCT health and healing. On a molecular level, CSIs decrease cellular proliferation, alter collagen and ECM composition, impede inflammatory pathways, decrease cellular viability, increase adipocyte differentiation, and increase apoptosis. These changes can be seen as early as 24 hours after corticosteroid exposure, last as long as 2 to 3 weeks, and are exacerbated by increased doses and decreased latency between doses. Biomechanical studies demonstrate that these changes result in decreased maximal load to failure, tendon stiffness, and suture anchor pull-out strength in rat shoulders up to 2 weeks but not at 3 and 4 weeks, post-CSI.

It has long been postulated that glucocorticoids have a negative effect on the homeostasis of collagen and tendons, and their role in the treatment of RCT remains a topic of debate..$^{8,9,35-37}$ On a histologic and molecular level, tendinopathy is the result of a mechanical insult followed by a persistent failure of a healing response. ${ }^{9,38}$ In the early stages of tendinopathy, it has been shown that an inflammatory response exists, which results in the recruitment of mononuclear phagocytes and expression of MMPs that promote tissue repair and angiogenesis. ${ }^{39,40}$ When the tendon continues to be stressed and subjected to further loads without adequate recovery time, the healing process fails, and tendinopathy progresses. ${ }^{39,40}$ Glucocorticoids appear to disrupt this healing process and facilitate the progression of tendinopathy via several mechanisms.

Our study found that glucocorticoids decrease the expression of MMPs and disrupt the physiologic inflammatory cascade by decreasing proinflammatory cytokines within the first week following exposure. The current study also elucidated that glucocorticoids induce cellular senescence, decrease viability, and induce apoptosis, perhaps by increasing excitotoxic $N$ methyl-D-aspartate receptor 1 glutamate receptors. These changes were found to be transient, lasting 1 to 3 weeks, but levels did not return to normal if samples were re-exposed within a 1 - to 2 -week time frame. These molecular and cellular effects manifested as decreased tensile strength and mechanical resistance of the RCT within 2 weeks of CSI in biomechanical studies. This finding supports the practice of allowing a minimum of 1 month after CSI to allow the tendon to re-establish its native biomechanical properties before performing arthroscopic RCR. Although the anti-inflammatory effects of CSIs may be favorable in terms of pain relief and temporary restoration of function, the impediment of inflammatory pathways and direct cellular damage prevent tendon healing and thus may promote progression of tendinopathy.

Despite conflicting evidence of efficacy, it is common clinical practice to prescribe CSIs in combination with physiotherapy to treat symptomatic RCTs. A recent systematic review and meta-analysis of randomized control trials studying the efficacy of CSIs on patients with RCT found that they provide at best minimal transient pain relief at 4 to 8 weeks, but no pain 
reduction was noted over the control at the 3 months assessment. ${ }^{2}$ However, this meta-analysis did state that the results were largely driven by a small number of studies with positive results that were significant outliers, and further, it remains unclear whether the decrease in pain observed in this study reached minimally clinical important difference. Similarly, the recent systematic review and non-pooled analysis by Cook et al. ${ }^{41}$ discovered that CSIs provided improvements in pain and function in the short term (up to 8 week) but not in the midterm (12-26 weeks). However, the results of this review only took into consideration 4 trials graded by the authors to be at low risk of bias: 3 of these trials showed benefit of CSI and 1 trial found no advantage over the control. The results of these 2 reviews are in contrast to the findings by the 2007 systematic review by Koester et al., ${ }^{3}$ which indicated that there is little reproducible evidence to support the efficacy of CSIs in managing RCT. Of note, an ongoing randomized controlled trial is currently investigating the effects of physical therapy with and without CSI for the treatment of rotator cuff disorders. ${ }^{42}$ The results of this study may shed light on the ability of CSIs to provide a window of opportunity to optimize rehabilitation following rotator cuff injury. This concept may be an important focus of future investigation.

While the relationship between injection dosage and clinical benefit or harm is uncertain, it has been shown in the study by Harada et al. ${ }^{22}$ that greater concentrations of triamcinolone acetonide caused irreversible changes in the viability and apoptosis ratios in human RCT biopsies, whereas reversible changes were observed in lower concentration formulations. This finding offers theoretical support to the practice of limiting the number of CSIs to 3 times per year, per body part, as greater concentrations have deleterious consequences with regards to tendon cellular viability. Although not supported by current clinical evidence, the findings of the studies by Muto et al. ${ }^{18}$ and Jo et al. ${ }^{24}$ suggest that platelet-rich plasma may partially reverse the deleterious effects that CSIs have on RCTs, which are findings that warrant further investigation.

\section{Limitations}

Our systematic review has limitations that are mostly the consequence of the quality and heterogeneity of the included studies. We specifically queried for papers that involved RCTs and the effect corticosteroids had on them. An important limitation in these included studies is they differ in whether the corticosteroid was exposed to the tissue in vivo or in vitro. The implications of these differences may have downstream effects and thus largely impact the outcome of each of those studies.
Several of these studies also used rat models, which must be interpreted with caution, as the biology and anatomy differ from that of humans. In addition, the laboratory studies were heterogeneous in terms of whether a healthy or pathologic RCT was being studied. This is an important variable to note, since it has been demonstrated that healthy tendon and diseased tendon have different microenvironments in terms of local inflammation, and thus they react differently to steroids. The degree to which the findings of these laboratory studies are applicable to human patients is certainly up for debate.

\section{Conclusions}

On a molecular level, CSIs decrease cellular proliferation, alter collagen and ECM composition, impede inflammatory pathways, decrease cellular viability, increase adipocyte differentiation, and increase apoptosis. These changes can be seen as early as 24 hours after corticosteroid exposure, last as long as 2 to 3 weeks, and are exacerbated by increased doses and decreased latency between doses. Biomechanical studies demonstrate that these changes result in decreased maximal load to failure, tendon stiffness, and suture anchor pullout strength in rat shoulders up to 2 weeks, but not at 3 and 4 weeks, post-CSI.

\section{References}

1. Chard MD, Cawston TE, Riley GP, Gresham GA, Hazleman BL. Rotator cuff degeneration and lateral epicondylitis: A comparative histological study. Ann Rheum Dis 1994;53:30-34.

2. Mohamadi A, Chan JJ, Claessen FM, Ring D, Chen NC. Corticosteroid injections give small and transient pain relief in rotator cuff tendinosis: A meta-analysis. Clin Orthop Relat Res 2017;475:232-243.

3. Koester MC, Dunn WR, Kuhn JE, Spindler KP. The efficacy of subacromial corticosteroid injection in the treatment of rotator cuff disease: A systematic review. J Am Acad Orthop Surg 2007;15:3-11.

4. Coombes BK, Bisset L, Vicenzino B. Efficacy and safety of corticosteroid injections and other injections for management of tendinopathy: A systematic review of randomised controlled trials. Lancet 2010;376:1751-1767.

5. Scott A, Docking S, Vicenzino B, et al. Sports and exerciserelated tendinopathies: A review of selected topical issues by participants of the second International Scientific Tendinopathy Symposium (ISTS) Vancouver 2012. Br J Sports Med 2013;47:536-544.

6. Arroll B, Goodyear-Smith F. Corticosteroid injections for painful shoulder: A meta-analysis. Br J Gen Pract 2005;55: 224-228.

7. Coombes BK, Bisset L, Brooks P, Khan A, Vicenzino B. Effect of corticosteroid injection, physiotherapy, or both on clinical outcomes in patients with unilateral lateral 
epicondylalgia: A randomized controlled trial. JAMA 2013;309:461-469.

8. Dean BJ, Lostis E, Oakley T, Rombach I, Morrey ME, Carr AJ. The risks and benefits of glucocorticoid treatment for tendinopathy: A systematic review of the effects of local glucocorticoid on tendon. Semin Arthritis Rheum 2014;43:570-576.

9. Dean BJ, Franklin SL, Carr AJ. A systematic review of the histological and molecular changes in rotator cuff disease. Bone Joint Res 2012;1:158-166.

10. Rees JD, Stride M, Scott A. Tendons-time to revisit inflammation. Br J Sports Med 2014;48:1553-1557.

11. Paavola M, Kannus P, Jarvinen TA, Jarvinen TL, Jozsa L, Jarvinen M. Treatment of tendon disorders. Is there a role for corticosteroid injection? Foot Ankle Clin 2002;7: 501-513.

12. Dean BJ, Franklin SL, Carr AJ. The peripheral neuronal phenotype is important in the pathogenesis of painful human tendinopathy: A systematic review. Clin Orthop Relat Res 2013;471:3036-3046.

13. Sharma P, Maffulli N. Biology of tendon injury: Healing, modeling and remodeling. J Musculoskelet Neuronal Interact 2006;6:181-190.

14. Ackermann PW, Li J, Lundeberg T, Kreicbergs A. Neuronal plasticity in relation to nociception and healing of rat achilles tendon. J Orthop Res 2003;21:432-441.

15. Sharma P, Maffulli N. Tendon injury and tendinopathy: Healing and repair. J Bone Joint Surg Am 2005;87:187-202.

16. Moher D, Liberati A, Tetzlaff J, Altman DG. Preferred reporting items for systematic reviews and meta-analyses: The PRISMA statement. Ann Intern Med 2009;151: 264-269.

17. Slim K, Nini E, Forestier D, Kwiatkowski F, Panis Y, Chipponi J. Methodological index for non-randomized studies (minors): Development and validation of a new instrument. ANZ J Surg 2003;73:712-716.

18. Muto T, Kokubu T, Mifune Y, et al. Platelet-rich plasma protects rotator cuff-derived cells from the deleterious effects of triamcinolone acetonide. J Orthop Res 2013;31: 976-982.

19. Lee HJ, Kim YS, Ok JH, Lee YK, Ha MY. Effect of a single subacromial prednisolone injection in acute rotator cuff tears in a rat model. Knee Surg Sports Traumatol Arthrosc 2015;23:555-561.

20. Dean BJ, Franklin SL, Murphy RJ, Javaid MK, Carr AJ. Glucocorticoids induce specific ion-channel-mediated toxicity in human rotator cuff tendon: A mechanism underpinning the ultimately deleterious effect of steroid injection in tendinopathy? Br J Sports Med 2014;48:1620-1626.

21. Tilley JM, Murphy RJ, Chaudhury S, Czernuszka JT, Carr AJ. Effect of tear size, corticosteroids and subacromial decompression surgery on the hierarchical structural properties of torn supraspinatus tendons. Bone Joint Res 2014;3:252-261.

22. Harada Y, Kokubu T, Mifune Y, et al. Dose- and timedependent effects of triamcinolone acetonide on human rotator cuff-derived cells. Bone Joint Res 2014;3:328-334.

23. Nakamura H, Gotoh M, Kanazawa T, et al. Effects of corticosteroids and hyaluronic acid on torn rotator cuff tendons in vitro and in rats. J Orthop Res 2015;33:1523-1530.
24. Jo CH, Lee SY, Yoon KS, Shin S. Effects of platelet-rich plasma with concomitant use of a corticosteroid on tenocytes from degenerative rotator cuff tears in interleukin lbeta-induced tendinopathic conditions. Am J Sports Med 2017;45:1141-1150.

25. Ramírez JP, Bonati-Richardson F, Garcia MP, et al. Intraarticular treatment with corticosteroids increases apoptosis in human rotator cuff tears. Connect Tissue Res 2019;60:283-290.

26. Ji JH, Kim YY, Patel K, et al. Dexamethasone facilitates NF-kappaB signal pathway in TNF-alpha stimulated rotator cuff tenocytes. J Microbiol Biotechnol 2019;29: 297-303.

27. Tempfer H, Gehwolf R, Lehner C, et al. Effects of crystalline glucocorticoid triamcinolone acetonide on cultered human supraspinatus tendon cells. Acta Orthop 2009;80:357-362.

28. Wei AS, Callaci JJ, Juknelis D, et al. The effect of corticosteroid on collagen expression in injured rotator cuff tendon. J Bone Joint Surg Am 2006;88:1331-1338.

29. Dolkart O, Chechik O, Bivas A, et al. Subacromial corticosteroid injections transiently decrease suture anchor pullout strength: Biomechanical studies in rats. J Shoulder Elbow Surg 2017;26:1789-1793.

30. Mikolyzk DK, Wei AS, Tonino P, et al. Effect of corticosteroids on the biomechanical strength of rat rotator cuff tendon. J Bone Joint Surg Am 2009;91:1172-1180.

31. Maman E, Yehuda C, Pritsch T, et al. Detrimental effect of repeated and single subacromial corticosteroid injections on the intact and injured rotator cuff: A biomechanical and imaging study in rats. Am J Sports Med 2015;44: 177-182.

32. Nuelle CW, Cook CR, Stoker AM, Cook JL, Sherman SL. In vitro toxicity of local anaesthetics and corticosteroids on supraspinatus tenocyte viability and metabolism. J Orthop Translat 2017;8:20-24.

33. Ghellioni GV, da Silva LS, Piovezan AP, Martins RO. Effect of methylprednisolone use on the rotator cuff in rats: Biomechanical and histological study. Rev Bras Ortop 2015;50:260-265.

34. Kim YS, Bigliani LU, Fujisawa M, et al. Stromal cellderived factor 1 (SDF-1, CXCL12) is increased in subacromial bursitis and downregulated by steroid and nonsteroidal anti-inflammatory agents. $J$ Orthop Res 2006;24:1756-1764.

35. Lubowitz JH, Brand JC, Rossi MJ. Preoperative shoulder corticosteroid injection is associated with revision after primary rotator cuff repair. Arthroscopy 2019;35:693-694.

36. Woolf SK. Editorial commentary: Steroid Injections prior to arthroscopic rotator cuff repair-is it time to rethink a conservative treatment paradigm? Arthroscopy 2019;35: 714-716.

37. Hasan SS, Timing is everything: Commentary on an article by Brian Forsythe, MD, et al. The Timing of Injections Prior to Arthroscopic Rotator Cuff Repair Impacts the Risk of Surgical Site Infection. J Bone Joint Surg Am 2019;101:e33.

38. Riley G. The pathogenesis of tendinopathy. A molecular perspective. Rheumatology 2003;43:131-142.

39. Millar NL, Hueber AJ, Reilly JH, et al. Inflammation is present in early human tendinopathy. Am J Sports Med 2010;38:2085-2091. 
40. Abate M, Gravare Silbernagel K, Siljeholm C, et al. Pathogenesis of tendinopathies: Inflammation or degeneration? Arthritis Res Ther 2009;11:235.

41. Cook T, Minns Lowe C, Maybury M, Lewis JS. Are corticosteroid injections more beneficial than anaesthetic injections alone in the management of rotator cuff-related shoulder pain? A systematic review. Br J Sports Med 2018;52:497.
42. Hopewell S, Keene DJ, Maia Schlussel M, et al. Clinical and cost-effectiveness of progressive exercise compared with best practice advice, with or without corticosteroid injection, for the treatment of rotator cuff disorders: protocol for a $2 \times 2$ factorial randomised controlled trial (the GRASP trial). BMJ Open 2017;7: e018004. 